\title{
Cash Flow Forecasting as an Element of Integrated Reporting: An Empirical Study
}

\author{
Kaspina R. G. ${ }^{1}$, Molotov L. A. ${ }^{1} \&$ Kaspin L. E. ${ }^{1}$ \\ ${ }^{1}$ Kazan Federal University, Institute of Management, Economics and Finance, Kazan, Russia \\ Correspondence: Kaspina R. G., Kazan Federal University, Institute of Management, Economics and Finance, \\ Kazan, 420008, Russia.
}

Received: December 27, 2014 Accepted: February 19, 2015 Online Published: April 30, 2015

doi:10.5539/ass.v11n11p89 URL: http://dx.doi.org/10.5539/ass.v11n11p89

\begin{abstract}
The article is devoted to the practical aspects of integrated reporting cash flow forecasts. The proposed formation method is based on the fuzzy logics and the procedure of expert evaluations.

As the result of a premade theoretical analysis of integrated reporting, an algorithm for cash flow forecasting has been developed. Additionally, an example of practical application of the covered method based on integrated reporting data of JSC Nizhnekamskneftekhim has been included.
\end{abstract}

Keywords: integrated reporting, forecasting, cash flow, fuzzy sets, expert evaluations, computer program

\section{Introduction}

The world economy is affected and dramatically changed by a myriad of factors. Among them, globalization, interdependence between economies, rapid population, consumption growth, and technological progress are leading contributors to this global fluctuation. Such changes have greatly increased the pressure on ecosystems that are simultaneously vital to both the economy and society.

Generally speaking, these changes affect the political, social and economical aspects in our lives. Therefore, if a company is to remain successful in the long term, it needs to respond to change by creating new innovative business models that contribute to an increase in production at the lowest cost resources (Kaspina, Khapugina, \& Zakirov, 2014a, 2014b).

In order to resolve this globally important issue, integrated reporting has continually developed over the past two decades. The idea of integrated reporting is in expansion and consolidation of the existing practical methods of reporting to create such a reporting structure, which would carry necessary information to fully estimate the value of a company in the XXI century (Kaspina \& Shneydman, 2013).

At its core, integrated reporting brings together the basic information regarding the plans of an organization, its corporate governance, the main indicators of activity, and its prospects of development in correspondence to the economic, social, and environmental surroundings of the organization.

The result is a clear vision of how management is set up within the organization, how it creates its value, and how it plans to recreate its value in the future. It is important to note that integrated reporting combines essential data partitions that are currently scattered in separate reports (e.g. financial statements, management notes, and corporate governance and remuneration reports on sustainable development) (Needles, Shigaev, Powers, \& Frigo, 2010, 2014).

Thus, integrated reporting combines and identifies the relationship between these sections, further explaining how they affect the likelihood of the organization to create and maintain its value in the short, medium and long terms.

The International Integrated Reporting Council published a prototype standard for the formation of integrated reporting. This standard contains the following elements:

- Fundamental concepts of integrated reporting.

- Fundamental principles regulating the content of integrated report and the way in which information should be presented. 
- The content of basic elements that should be included in integrated report.

- Recommendations for the preparation and presentation of integrated report.

To determine the content of integrated report, these principles (which are based on the following six elements) should be applied:

- Overview of the organizational structure and business model.

- The environment in which an organization operates (including the risks and opportunities).

- Strategic goals and strategies to achieve these goals.

- Corporate governance and remuneration.

- Performance

- Prediction (prospects) of the future.

In this article, we consider a specific element of integrated report, namely the practical aspects of forming the forecast as well as the challenges and uncertainties an organization may face, and how to overcome them (Brown \& Christensen, 2014; Goodman, Neamtiu, Shroff, \& White, 2014).

Our analysis of integrated reporting of leading Russian companies allowed us to identify sources of cash flows and direction of spending for three types of activity: current (operating), investing, and financing. Information regarding the organization's cash flow aids the setup for necessary integrity between financial and management accounting data. Nevertheless, being a crucial element of integrated reporting, evaluation of cash flow should not be considered separately from other reporting indicators.

Next, we will briefly describe the usefulness of cash flow information as part of integrated reporting, divided by types of cash flow (Figure 1).

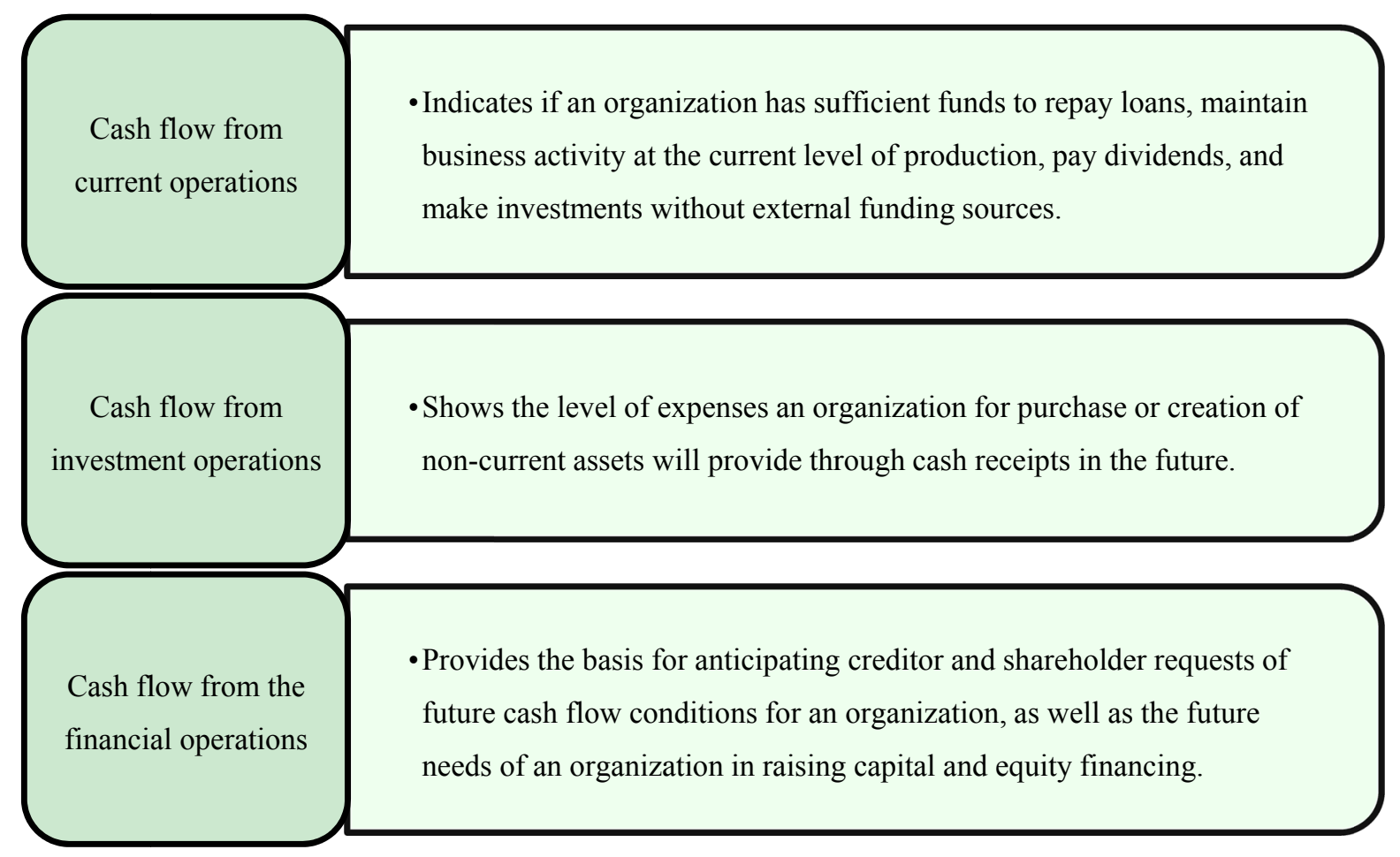

Figure 1. Usefulness of cash flow information

Based on the utility analysis, we distinguish three groups of users whose interests are significantly different. Shareholders, investors, lenders, and financial experts will be interested in yields, return on invested capital, and the value of the company defined as the future cash flow at the current valuation. This, along with the FCF (free cash flow) index, it is imperative that managers are informed of the evaluation of market prospects and interests of state agencies based on the concept of redistribution of resources (Kaspina \& Plotnikova, 2014). 
Regardless of the category of interested users, forecasting is carried out to build a set of possible decisions. An attempt to "look into the future" is inextricably linked with the risk of non-compliance for the future results of business activities.

At this point, the main principle and important criteria of quality of economic prediction is minimizing the risk of failure. The presence of this risk, and the need to minimize it, are the greatest factors to consider when contributing to a high degree of difficulty forecasting, the multiplicity of its stages, and the techniques being employed. This includes the interdisciplinary aspects, as well as the importance of checking the consistency of assumptions.

\section{Method}

A Russian corporations' cash flow forecast as a part of an integrated financial statement requires innovative approaches due to companies having neither profits nor positive cash flow from operating activities (keep in mind that comparable data regarding a number of previous periods and a group of companies with comparable statements are largely unavailable) (Cormier, Lapointe-Antunes, \& Mcconomy, 2014).

Now let us consider the existing methods of financial and economic forecasting. Conventionally, they will be divided into two major groups: factual (formal) and expert (intuitive).

Factual (formal) methods are based on available information with regards to a prediction (Markaryan, Snetkova, $\&$ Khairullina, 2014). The expert (intuitive) methods employ the opinions of both specialists and experts, and are used when studied processes are impossible to formalize or when there is varying degrees of uncertainty within the data.

However, different experts will have varying opinions when evaluating an index,-often finding it difficult to provide exact estimates. The nature of estimation is one that relies on subjective perception, thus making it difficult to be defined in terms of absolutes. In such situations, we suggest using the fuzzy-sets method which works with indicators in the form of fuzzy numbers (Zayed \& Liu, 2014).

Fuzzy logic is one of the most promising areas of research in the field of analysis, forecasting, modeling of economic phenomena, and processes. Today, constructing models of approximate reasoning and their use in computer systems is one of the leading problems in the science field. Therefore, both economic-mathematical modeling and the procedure of expert evaluations should be used in cash flow forecasting.

Economic-mathematical modeling allows a certain degree of reliability to establish dynamics within the parameters of conditional factors, further affecting the development of financial processes in the future. In order to obtain a more reliable financial forecast, economic-mathematical modeling is supplemented by expert evaluations, allowing us to adjust quantitative values of financial processes.

The construction of a long-term forecast is widely regarded as a complex issue. Notably, the risk of business activity and forecast should not be overlooked.

The first can be reduced by involving a group of experts from the organization itself, while the second can be reduced by the use of accumulated experience and creating multiple simulations of business activities (e.g. creating several versions of the forecast report, including both optimistic and pessimistic findings).

After using the factual method to determine a predictive value for said financial indicator in the integrated report, we will move on to the adjustments of this value with the help of an expert group.

To do this, we shall describe the algorithm for constructing the membership function (MF) of fuzzy numbers represented in Formula 1, using the function of the form (Zayed \& Liu, 2014)

$$
\mu_{K}(u)=e^{-\alpha(K-u)^{2}}, u \in U,
$$

where: $U$ - universal set (in the general case of a set of real numbers), then we build numbers' MF approximately equal to some number $K$, where the parameter $\alpha$ (Formula 2) (Yan, Hall, \& Turner, 2014) depends on the fuzzy degree $\mu_{K}(u)$. The value $\alpha$ is determined from the expression

$$
\alpha=\frac{-4 \ln 0,5}{(\beta(K))^{2}},
$$

where: $\beta(K)$ - the distance between the transition points for $\mu_{K}(u)$, where MF is set to 0.5 (we denote these points by $a$ and $\mathrm{b}$, assuming that $\beta(K)=b-a$ ).

Next, we go directly to the fuzzy sets method which is based on the described algorithm for constructing MF of fuzzy numbers. This method does the initial forecast interval sequential narrowing to the corresponding fuzzy number. 
The initial forecasting interval is generally based upon the group expertise determining the minimum and maximum values. This interval is an input parameter of the iterative procedure to obtain the forecast fuzzy number.

To narrow the interval to the forecast fuzzy number, the iterative procedure must consist of the following steps:

1) The current iteration interval is divided into three overlapping sub-intervals of equal length, while their priorities are identified according to Saaty's method of analysis of hierarchies (Zadeh, 1978).

2) The interval is narrowed (with the priorities being taken into account) and compared with the confidence interval of the fuzzy number (alpha-section at 0.5 level). If the current interval fits within the confidence interval, than the iterations are terminated. Otherwise, new iteration is performed to narrow the range of the forecast. Forecast value of the index is defined as a fuzzy number obtained in the last iteration.

Step by step description of the algorithm of fuzzy forecasting method has the following form (Zayed \& Liu, 2014).

- Statement of the problem of forecasting.

- Formation of an expert group consisting of M people.

- Determination of the initial interval based on the experts' survey (as described in formula 3) (Zayed \& Liu, 2014):

$$
A=\left\{\left(a_{1}, \overline{a_{l}}\right), i=\overline{1, M}\right\},
$$

where: $a_{1}, \overline{a_{l}}$ - are the minimum and maximum values of the initial interval of expert $i$.

- building the group initial interval (formula 4) (Zayed \& Liu, 2014):

$$
(\underline{m}, \bar{m}), \underline{m}=\min \left\{a_{i}, i=\overline{1, M}\right\}, \bar{m}=\max \left\{\overline{a_{i}}, i=\overline{1, M}\right\} ;
$$

- definition of fuzzy number $\widetilde{P}$ "is approximately equal to $(\underline{m}+\bar{m}) / 2$ " and its interval $\beta$ at $0.5 \mathrm{MF}$ level.

- checking if the current interval fits the confidence interval of fuzzy number (formula 5 ):

$$
(\underline{m}-\bar{m}) \leq \beta \text {. }
$$

If the embedding condition is satisfied, than jump directly to the step which determines the forecast interval; if it is not satisfied, than proceed with the fuzzy forecasting method:

- formation of alternatives for current interval by partition to three overlapping sub-interval (with the overlap degree of $50 \%$ ).

- Formation of individual experts' matrices of pairwise comparisons (MPC) alternatives on the degree of preference.

- defining group MPS alternatives by defining its elements as the geometric mean of the corresponding elements of individual MPSs.

- calculation of the group priorities alternatives vector (Formula 6):

$$
\boldsymbol{p}=\left(p_{1}, p_{2}, p_{3}\right)
$$

- definition of forecast interval using formula 7:

$$
(\underline{m}, \bar{m}), \underline{m}=p_{1} \underline{a_{1}}+p_{2} \underline{a_{2}}+p_{3} \underline{a_{3}}, \bar{m}=p_{1} \overline{a_{1}}+p_{2} \overline{a_{2}}+p_{3} \overline{a_{3}},
$$

and moving back to the stage of defining fuzzy number $P$ and its MF.

\section{Result}

The result of this work has become the construction of a phased model to forecast cash flow as a part of integrated reporting.

The purpose has been determined: the formation of forecast cash flow as a part of integrated reporting.

We propose the following forecast implementation plan (Figure 2):

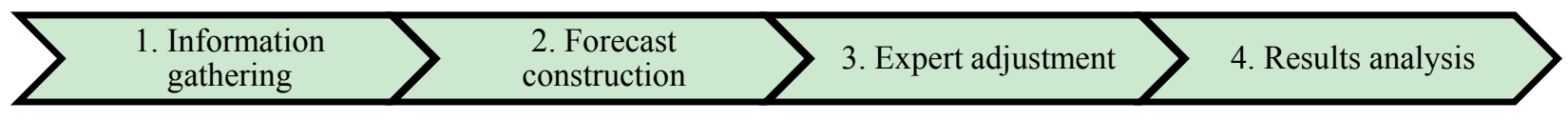

Figure 2. Cash flow Forecasting: Implementation Stages 
The following example of forecasting cash balance at end of the period (thou. rubles) has been built using integrated reporting data of JSC Nizhnekamskneftekhim (Table 1) (Annual report of JSC "Nizhnekamskneftekhim", 2013).

To comply with the conditions of trade secrets, certain values have deliberately been distorted.

Table 1. Cash at the end of the period of JSC Nizhnekamskneftekhim (thou. rubles)

\begin{tabular}{cc}
\hline Reporting period & Cash at the end of the period of Nizhnekamskneftekhim (thou. rubles). \\
\hline 2009 & 1086517 \\
2010 & 695922 \\
2011 & 3313525 \\
2012 & 2808446 \\
\hline
\end{tabular}

Summary table of predicted values cash balance at the end of 2013 are given in Table 2.

Table 2. Summary table of predicted values cash balance at the end of 2013 JSC Nizhnekamskneftekhim (thou. rubles)

\begin{tabular}{|c|c|c|}
\hline \multicolumn{2}{|c|}{ Type of the forecast } & Cash balance at the end of 2013 (thou. rubles) \\
\hline \multicolumn{2}{|c|}{ The trend forecast } & 3681205 \\
\hline \multirow{2}{*}{ Expert adjustment } & The initial group interval & [ $2950000-3650000$ ] \\
\hline & The fuzzy number & 3280500 \\
\hline \multicolumn{2}{|c|}{ Real data } & 3125202 \\
\hline
\end{tabular}

Analysis of the results showed that the actual value deviation of the indicator cash balance built by a computer trend was $17.8 \%$, while the fuzzy group examination forecast has a deviation of only $4.8 \%$. Once again this proves the method's viability in terms of its application in forecasting financial performance.

\section{Conclusion}

Building an effective business system is impossible without proper and timely formatted forecast statements as a part of integrated reporting. The proposed fuzzy sets forecasting algorithm provides the necessary mechanism for this process.

It should also be noted that the described method of fuzzy forecasting and the associated computer program presented in this article are sufficiently universal and will increase the reliability of the decision making process in a wide range of financial and economic systems.

\section{References}

Annual report of JSC “Nizhnekamskneftekhim”. (2013). Retrieved from http://otchet/nknh-otchet-eng-2013.pdf

Brown, N. C., \& Christensen, T. E. (2014). The quality of street cash flow from operations. Review of Accounting Studies, 19(2), 913-954. http://dx.doi.org/10.1007/s11142-014-9276-9

Cormier, D., Lapointe-Antunes, P., \& Mcconomy, B. J. (2014). Forecasts in IPO Prospectuses: The Effect of Corporate Governance on Earnings Management. Journal of Business Finance and Accounting, 41(1-2), 100-127. http://dx.doi.org/10.1111/jbfa. 12060

Goodman, T. H., Neamtiu, M., Shroff, N., \& White, H. D. (2014). Management forecast quality and capital investment. Accounting Review, 89(1), 331-365. http://dx.doi.org/10.2308/accr-50575

Kaspina, R. G., \& Plotnikova, L. A. (2014). Accounting of external economic activity of Russian companies: Experience and difficulties. Life Science Journal, 11(11), 108-111.

Kaspina, R. G., \& Shneydman, L. Z. (2013). New approach to the oil companies' corporate reporting. Neftyanoe Khozyaistvo - Oil Industry, 9, 14-17.

Kaspina, R. G., Khapugina, L. S., \& Zakirov, E. A. (2014a). Employment of activity-based costing in the process 
of company business model generation. Life Science Journal, 11(8), 356-359.

Kaspina, R. G., Khapugina, L. S., \& Zakirov, E. A. (2014b). Interrelation of Company's Business Model Structure and Information Disclosed in Management Reporting. Life Science Journal, 11(12), 778-780.

Markaryan, S. E., Snetkova, T. A., \& Khairullina, D. V. (2014). Administrative aspects of accounting organization. Russian experience and problems. Life Science Journal, 11(8), 107-111.

Needles, B. E. Jr., Shigaev, A., Powers, M., \& Frigo, M. L. (2010). Strategy and integrated financial ratio performance measures: A longitudinal multi-country study of high performance companies. Studies in Managerial and Financial Accounting, 20, 211-252. http://dx.doi.org/10.1108/S1479-3512(2010)00000 20011

Needles, B. E. Jr., Shigaev, A., Powers, M., \& Frigo, M. L. (2014). Operating characteristics of high performance companies: Strategic direction for management. Studies in Managerial and Financial Accounting, 28, 25-51. http://dx.doi.org/10.1108/S1479-351220140000028008

Saaty, T. L. (1980). The Analytic Hierarchy Process: Planning, Priority Setting, Resource Allocation (pp. 136-149). New York: McGraw-Hill International Book Company.

Yan, M., Hall, M. J. B., \& Turner, P. (2014). Estimating liquidity risk using the exposure-based cash-flow-at-risk approach: An application to the UK banking sector. International Journal of Finance and Economics, 19(3), 225-238. http://dx.doi.org/10.1002/ijfe.1495

Zadeh, L. A. (1978). Fuzzy sets as a basis for a theory of possibility. Fuzzy Sets and Systems, 1(1), 3-28. http://dx.doi.org/10.1016/0165-0114(78)90029-5

Zayed, T., \& Liu, Y. (2014). Cash flow modeling for Construction projects. Engineering, Construction and Architectural Management, 21(2), 170-189. http://dx.doi.org/10.1108/ECAM-08-2012-0082

\section{Copyrights}

Copyright for this article is retained by the author(s), with first publication rights granted to the journal.

This is an open-access article distributed under the terms and conditions of the Creative Commons Attribution license (http://creativecommons.org/licenses/by/3.0/). 